\title{
KONTRUKSI KEGILAAN DALAM NOVEL LADY AUDLEY'S SECRET KARYA MARY ELIZABETH BRADDON
}

\author{
Zietha Arlamanda Asri \\ Universitas Islam Negeri Sunan Gunung Djati Bandung \\ ziethahikaru@gmail.com
}

Artikel diterima: 01 Juni 2020

Artikel direvisi: 13 Juli 2020

Artikel disetujui: 26 Agustus 2020

\begin{abstract}
Abstrak
Permasalahan mengenai kegilaan sering menjadi tema para penulis sastra. Tema ini juga banyak hadir di karya sastra pada era Victoria. Para penulis besar menghadirkan narasi mengenai para perempuan yang berstrategi untuk menghindari budaya patriarki, namun tidak ingin dijebloskan ke dalam suaka. Hal ini juga terjadi pada karakter utama dalam novel Lady Audley's Secret (1862) karya Mary Elizabeth Braddon. Lucy Graham tumbuh dalam kemiskinan, ia sangat peduli dengan peningkatan status sosial dan keuangannya. Fakta bahwa ibunya dilembagakan karena kegilaan juga telah menghantui Lucy sepanjang waktu. Dia menikahi orang-orang kaya seperti George Talboys dan Robert Audley, namun berakhir dengan budaya patriarki yang sangat keras yang membawanya pada kegilaan. Dengan demikian, penelitian ini bertujuan untuk mengetahui bagaimana tokoh Lucy dikonstruksi menjadi "orang gila" dalam pandangan masyarakat Victoria. Untuk menjawab permasalahan penelitian, penulis menggunakan analisis tekstual sebagai metode penelitiannya. Teori yang digunakan untuk membantu analisis yakni perspektif yang diusulkan oleh Foucault mengenai konstruksi kegilaanyang terjadi pada subjek. Hasil penelitian menunjukkan bahwa tindakan yang manipulatif serta culas yang dilakukan oleh Lucy dinilai sebagai suatu kegilaan dan tidak sesuai dengan norma serta nilai pada era tersebut. Pada akhirnya ia pun dimasukkan ke dalam rumah sakit jiwa dan meninggal di dalamnya.
\end{abstract}

\begin{abstract}
The issue of madness is often the main focus of the writers. The theme of madness is also present in many literary works in the Victorian era. Major writers present narratives about women who have a strategy to avoid patriotic culture, but do not want to be thrown into asylum. Those also happened to the main character in the novel Lady Audley's Secret (1862) by Mary Elizabeth Braddon. Lucy Graham grew up in poverty; she was very concerned with improving her social and financial status. The fact that his mother was institutionalized by insanity had haunted Lucy all the time. She married wealthy people such George Talboys and Robert Audley, but ended up with a very strict patriarchal culture which brought her to madness. Thus, this study aims to find out how Lucy's character is constructed to become a "crazy person" in the view of Victorian society. To answer the research problem, this study uses textual analysis as its research method. The theory used to help the analysis is the perspective proposed by Foucault regarding the construction of madness that occurs on the subject. The results show that manipulative and nasty actions committed by Lucy were considered as insanity and not in accordance with the norms and values of the era. In the end she was put into asylum and died in it.
\end{abstract}

Keywords: Madness, Foucault, Lady Audley's Secret, Mary Elizabeth Braddon 


\section{Pendahuluan}

Kegilaan acap kali menjadi tema-tema besar dalam suatu karya sastra. Pada periode Victoria di Inggris, bermunculan penulis dengan narasi mengenai kegilaan. Narasinarasi tersebut lahir dari dinamika yang terjadi pada periode tersebut. Seperti yang selalu digaungkan bahwa karya sastra bukanlah lahir dari kekosongan sebuah budaya. Atas pondasi itu, tema mengenai kegilaan yang dituangkan oleh para penulis merupakan representasi dari keadaan realitas sosial yang tengah terjadi kala itu. Karya sastra dipandang sebagai gambaran zaman tempat ia lahir dan sebuah rekaman apa yang telah terjadi.

Di era Victoria, para novelis besar menikmati berkutat dengan masalah sosial yang mendesak pada saat itu. Karya mereka mencerminkan serta membentuk sikap masyarakat terkait dengan masalah kontemporer mengenai kegilaan. Para penulis khususnya menyoroti kegilaan yang terjadi pada para perempuan Victoria. Banyak sekali karya sastra yang menarasikan pertarungan tokoh perempuan dalam mempertahankan akal sehat di antara tekanan nilai, moralitas, serta budaya yang meletakan perempuan sebagai yang tunduk dan tertindas. Para perempuan terkungkung dalam kondisi patriarki yang begitu kuat, baik kalangan bawah, menengah, maupun atas. Kaitan antara masyarakat Victoria patriarki dan penyakit mental yang lazim di kalangan perempuan Victoria dapat diklarifikasi oleh definisi kegilaan dari filsuf Prancis Michel Foucault. Dalam bukunya, Madness and Civilization: A History of Insanity in the Age of Reason (1989), Foucault mempelajari sejarah kegilaan dalam masyarakat Barat. Investigasi Foucault menunjukkan bahwa berbagai jenis perilaku telah dianggap gila pada waktu yang berbeda dan pada masyarakat yang berbeda. Foucault juga menekankan peran penting dari konfigurasi kekuasaan, masyarakat, atau ideologi dalam mendefinisikan kegilaan dalam waktu tertentu. Dengan kata lain, kegilaan dibangun secara sosial. Dengan demikian, dalam masyarakat patriarki era Victoria yang meletakkan kekuasaan pada laki-laki, mereka dapat mendefinisikan kegilaan secara umum (dan perempuan gila khususnya) untuk membangun kedaulatan mereka sendiri. Perempuan Victoria, yang menjadi sasaran marginalisasi seperti itu mengejar berbagai jenis strategi untuk menghindari penindasan dan suaka patriarkal. Salah satu penulis dengan karya-karyanya yang menggambarkan perempuan era Victoria diambang kegilaan ialah Mary Elizabeth Braddon. Salah satu karya Braddon yang kental dengan patriarki serta kegilaan yaitu novel Lady Audley's Secret. Novel Lady Audley's Secret. Sejauh ini novel tersebut merupakan yang paling populer dan best seller yang pada akhirnya membuat Braddon dilabeli dengan julukan "Queen of the Circulating Libraries" (Bernstein, 1994).

Lady Audley's Secret mengisahkan seorang perempuan yang bernama Lucy Graham yang telah menjalani kehidupan menyedihkan dengan suaminya yang bernama George Talboys. Geroge sebenarnya orang berada, namun kemudian diasingkan oleh ayahnya karena menikahi istrinya yang miskin. Setelah tinggal bersama sang suami yang tidak memiliki hak waris, dia kecewa dan sedih. Akan tetapi, Lucy tidak dapat berbuat banyak dan masih patuh terhadap sang suami. George pada akhirnya, memutuskan untuk pergi ke Australia guna mencari uang. George menghilang selama tiga setengah tahun, meninggalkan istri dan 
putranya. Selama itu, Lucy berusaha dengan keras untuk menjadi perempuan yang layak di mata masyarakat.

Lucy mencoba memenuhi harapan keras suaminya serta masyarakat untuk menjadi perempuan yang baik dan tunduk pada budaya patriarki. Budaya keras ini membuat Lucy kesulitan untuk melanjutkan hidup karena dia begitu tertekan secara psikologis. Lucy harus menemukan cara untuk menghindari kemiskinan dalam masyarakat patriarki, sebab semenjak ditinggalkan oleh George, Lucy menjadi tulang punggung. Setelah menikah lagi dengan seorang laki-laki tua kaya bernama Robert Audley, Lucy masih harus tunduk pada patriarki yang bahkan lebih keras dari sebelumnya.

Novel ini menunjukkan kehidupan Inggris, khususnya di era Victoria di abad ke19 yang budaya, adat istiadat, dan norma sosialnya sangat lekat dengan patriarki. Hal ini menjadi aturan standar untuk setiap anggota masyarakat yang dihormati, dipatuhi, dan dijalankan tanpa pernah mempertanyakan kelayakannya. Bagi Lucy, sebagai seorang wanita, ia dapat dikatakan tidak memiliki hak suara untuk menentukan cara hidup pribadinya. Hal ini karena perempuan adalah pendamping dan pendukung kemauan dan kehormatan lakilaki, terutama pasangannya masing-masing. Pengabdian kepada keluarga adalah sesuatu yang mutlak dan harus dipenuhi oleh perempuan di era tersebut.

Narasi Braddon dalam novel Lady Audley's Secret menghadirkan Lucy sebagai tokoh perempuan yang hidup dalam cengkeraman kemiskinan serta nilai, moral dan budaya yang didominasi oleh kekuasaan laki-laki. Hal tersebut, mengubah pola pikir dan tingkah laku Lucy. Kemewahan serta tekanan menjadi begitu ironi yang terjadi sepanjang narasi dalam novel. Hal tersebut mendorong tokoh perempuan ini untuk kemudian melawan norma serta nilai yang ada di era Victoria, sedangkan siapa pun yang melawan nilai dominan pada suatu periode tertentu maka akan dilabeli sebagai orang gila. Oleh karena itu, tujuan dari penelitian ini adalah untuk melihat proses konstruksi kegilaan yang terjadi padatokoh wanita Inggris, yang diwakili oleh Lucy Talboys.

Dalam penelitian ini, penulis menggunakan analisis tekstual sebagai metode penelitian. Faruk (2012:25) mengemukakan bahwa metode dan teknik pengumpulan data ini pada dasarnya adalah seperangkat cara atau teknik yang merupakan perpanjangan dari indera manusia karena tujuannya adalah mengumpulkan fakta-fakta empirik yang terkait dengan masalah penelitian. Berdasarkan hal tersebut, metode pengumpulan data ini menjadi hal yang cukup penting dalam penelitian ini. Pengumpulan data diawali proses pembacaan pada objek material penelitian, dalam hal ini objek penelitian tersebut adalah novel Lady Audley's Secret (1862) karya Mary Elizabeth Braddon. Dengan demikian, data dalam bentuk teks dari novel. Data yang dikumpulkan kemudian dianalisis dengan menerapkan konsep kegilaan yang dicetuskan oleh salah satu pasca-strukturalis yaitu Michel Foucault sebagai objek formal. Pada titik ini, proses dilakukan dengan menyiapkan dan mengatur data, membaca data, menganalisis data dengan membuat kategori, dan akhirnya menafsirkan data. Selanjutnya, berdasarkan pada permasalahan dalam penelitian, konsep-konsep teoritis mengenai kegilaan yang digagas oleh Foucault digunakan untuk mengetahui konstruksi kegilaan yang ada dalam novel Lady Audley's 
Secret.

Berdasarkan investigasi yang telah dilakukan, ditemukan bahwa tidak ada penelitian yang mengeksplorasi konstruksi kegilaan dalam novel Lady Audley's Secret karya Mary Elizabeth Braddon dengan menerapkan teori Michel Foucault. Hasil pemetaan yang telah disaring sesuai relevansinya dengan penelitian ini menunjukkan bahwa ada dua penelitian yang memiliki objek material yang sama dan satu studi yang memiliki objek formal yang serupa dengan penelitian ini.

Penelitian pertama yaitu dari sebuah senior tesis yang ditulis oleh Corey Hayes (2014) berjudul The Beauty and the Barrister Gender Roles, Madness, and the Basis for Identity in Lady Audley's Secret. Penelitian ini membahas konsep identitas dalam novel Lady Audley's Secret. Peneliti mengkaji mengenai peran gender dan tema kegilaan untuk mengkritik konsepsi Victoria tentang identitas. Penelitian lain yaitu berupa artikel jurnal oleh Shaqayeq Moqari (2015) dengan judul Representation of Mad Woman in Lady Audley's Secret by Mary Elizabeth Braddon. Moqari membahas perilaku tokoh utama dalam novel yaitu Lady Audley melalui konsep feminis. Penelitian ini melihat perilaku transgresif sebagai ekspresi pemberontakan seorang perempuan ketika di dominasi oleh budaya patriarki yang sangat kental serta membahas kepasifan sebagai hukuman dalam novel tersebut.

Sedangkan untuk objek formal, penelitian pertama ditulis oleh Langgeng Prima Anggradinata (2016) dengan artikel jurnalnya yang berjudul Konsep Kegilaan dan Kekuasaan Michel Foucault dalam Cerpen "Catatan Harian Orang Gila" Karya Lu Xun. Dalam penelitian ini, konsep Michel Foucault mengenai kekuasaan dan kegilaan digunakan untuk memperoleh makna yang lebih dalam pada cerpen "Catatan Harian Orang Gila". Unsur tokoh serta penokohan dalam cerpen menjadi gerbang untuk menelaah hubungan antara ilmu pengetahuan, kegilaan, epistemé, serta kekuasaan dalam cerpen. Hubungan-hubungan yang ada dalam karya itu membentuk suatu makna yaitu penguasaan terhadap tokoh "Aku" dalam cerpen.

Penelitian ini menggunakan konsep mengenai kegilaan yang dicetuskan oleh Michel Foucault. Awal konsep kegilaan yang digagas Oleh Foucault berasal dari kritik mengenai permasalahan moralitas. Lebih mendalam lagi, kritik ini tidak hanya ditujukan untuk melawan atau mengadakan pembalikan terhadap nilainilai yang sudah ada, tetapi juga kritik terhadap krisis rasionalitas modern orang Eropa saat itu. Foucault mempersoalkan legitimasi rasionalitas modern untuk menciptakan kategori-kategori kegilaan. Hal tersebut terjadi, karena fenomena mengenai kegilaan menjadi suatu permasalahan sosial dan dianggap sebagai objek dari kekosongan budaya, khususnya pada era Pencerahan (Renaissance). Kekosongan budaya terjadi karena sebelum permasalahan tersebut timbul,wabah penyakit lepra lebih dulu mendatangkan kekalutan bagi masyarakat Eropa. Setelah wabah tersebut mereda, kegilaan menjadi pengisi nilai-nilai moral masyarakat yang kosong. Maksudnya, dalam masyarakat harus ada nilai atau batas antara sehat dan yang tidak, dengan kata lain, terdapat batasan normal dan gila. Manusia yang dianggap gila ialah manusia yang tidak memiliki nilai-nilai moral itu, yaitu ketika seseorang bertentangan dengan nilai ataupun norma yang berlaku pada masa manusia tersebut hidup.

Foucault menunjukkan bahwa kegilaan 
bukanlah sekadar masalah empiris atau medis, melainkan berkaitan dengan normanorma sosial dan bentuk-bentuk diskurus yang berlaku pada periode sejarah tertentu. Dengan meneliti sejarah kegilaan dalam kaitannya dengan peradaban manusia, Foucault menunjukkan salah satu faktor penting yang acap kali diabaikan padahal sangat memengaruhi cara manusia melihat dirinya, yakni masyarakat dan masa depannya. Pengertian tentang kegilaan itu diciptakan oleh manusia. Perlakuan semacam inilah yang membuat manusia secara tidak sadar menciptakan kerangkeng-kerangkeng bagi dirinya sendiri. Kerangkeng-kerangkeng inilah yang disebut moralitas.

Dalam bukunya Madness and Civilizations (1989), tidak hanya menunjukkan bagaimana status kegilaan itu lahir, bagaimana munculnya ilmu-ilmu psikiatri dan psikologi, namun ia berkata bahwa ia sedang menulis arkeologi pembungkaman. Orang gila, secara periodik, terus-menerus dibungkam, dan tidak diperbolehkan berdialog lagi dengan nalar. Secara terperinci, Foucault memaparkan bahwa dalam setiap masyarakat (baca: peradaban) selalu ditemukan orang-orang yang berperilaku berbeda dari yang lain. Perbedaan ini mencakup di semua wilayah aktivitas manusia. Foucault (2002:105) pun membagi wilayah aktivitas manusia ini ke dalam empat kategori yaitu buruh atau produksi ekonomi, seksualitas atau keluarga yakni reproduksi masyarakat, bahasa dan pengucapan, serta aktivitas yang menggelikan seperti permainan dan festival-festival. Mereka yang berperilaku berbeda, yang tampak tidak sesuai dengan aturan-aturan yang terbatasi dalam empat wilayah di atas, disebut sebagai individu-individu yang marginal.
Foucault (dalam Ritzer, 2009) memaparkan perkembangan kegilaan dari periode Renaisans. Pada masa itu, orang gila bebas berkeliaran, tetapi pada akhirnya mereka pun ditanggulangi dengan cara dimasukkan ke dalam kapal laut dan dibiarkan terombangambing. Kemudian dalam perkembangannya, kapal yang mengangkut para orang gila tersebut diubah menjadi The House of Correction (rumah koreksi). The House of correction tersebut dibangun untuk mengatasi persoalan sosial karena pada era ini kepekaan sosial telah terbentuk, lebih dari itu rumah tersebut tidak ubahnya seperti penjara. Diharuskan adanya tindakan untuk mengatasi persoalan sosial seperti kemiskinan, pengangguran, dan kegilaan. Maka dari itu, untuk mengatasi hal tersebut, didirikanlah rumah koreksi. Pada tahap ini, masalah media penyelesaian menjadi berubah ketika sebelumnya kapal menjadi tempat pemberangkatan, di sisi lain rumah koreksi menjadi tempat pengurungan. Rumah tersebut mengurung para pengangguran, orang malas, orang sakit, gelandangan, serta orang gila yang dinilai menjadi permasalahan sosial yang meresahkan.

Kemudian secara berangsur-angsur, pada abad ke-18, pengurungan mulai dinilai sebagai suatu kesalahan. Orang-orang yang telah dikurung mulai dibebaskan dari rumah koreksi. Namun yang dibebaskan hanyalah orang sakit, lanjut usia, pemalas, dan pelacur. Orang gila dibiarkan ada dalam penjara. Orang-orang ini yang kemudian dianggap memiliki masalah dengan sebab psikologis dan karakteristiknya sendiri. Dalam Ilmu Psikologi dan Psikiatri di era Victoria (sekitar abad 19) akhirnya benarbenar memisahkan orang gila dari orang waras, karena penemuan kegilaan pada abad ke-18. Bagi Foucault, psikologi dan psikiatri 
merupakan perusahaan moral dan bukan usaha keilmuan, kedua hal tersebut bertujuan memerangi orang yang secara progresif tidak sanggup menjaga dirinya sendiri. Foucault memahami ketika seseorang telah divonis menjadi orang gila, maka hukuman kurungan siap menanti mereka dan menjadi dalih sebagai pertolongan. Para physician (dokter/tabib) memainkan peran sentral di rumah sakit dan di tempat lainnya, tidak sebagai ilmuwan, tetapi sebagai jaminan hukum dan moral yang dianggap dapat menyelesaikan persoalan mengenai kegilaan.

Kegilaan yang suatu waktu dianggap penyakit pada tubuh, beralih dipandang sebagai penyakit pada memori atau ingatan. Apa yang dulu dirasa sebagai kebutuhan jasmani, sekarang dianggap menjadi kebutuhan mental. Oleh karena itu, hal tersebut diidentikkan dengan immoralitas, yaitu kesalahan yang pada akhirnya disejajarkan dengan penyakit-sakit yang dipahami sebagai efek psikologi ketidakhadiran moral. Pemahaman ini meluas pada dasar kajian ilmu psikiatri di abad ke-19 serta metode moralnya. Pada akhirnya, diketahui bahwa kegilaan dinilai sebagai yang bertentangan dengan moral, yang merupakan hasil ciptaan kelompok ataupun rezim tertentu. Ketika seseorang berbeda, mereka akan dibatasi dan disingkirkan. Orang-orang tersebut dilabeli menjadi pembohong dan dinilai menghambat kepentingan mereka. Jika seseorang berkata bahwa kamu gila maupun tidak waras, itu menandakan bahwa kamu bukan termasuk kelompok mereka. Pada akhirnya mereka akan diasingkan serta dikucilkan dalam segala hal, singkatnya mereka dianggap sebagaiorang gila.

\section{Konstruksi Kegilaan dalam Novel Lady Audley's Secret Karya Mary Elizabeth Braddon}

Topik utama yang ada dalam novel Lady Audley's Secret ialah kegilaan yang terkontraksi secara apik. Kegilaan dihasilkan dari budaya patriarki yang pada akhirnya mengharuskan seorang perempuan menjadi tertindas dan lemah. Ada peran gender yang tradisional membentuk pola pikir masyarakat Victoria. Wanita yang feminin dan pria yang maskulin merupakan identitas dari peran yang diberikan oleh masyarakat kepada mereka. Gagasan pria sebagai yang kuat untuk rumah tangganya dan wanita sebagai malaikat dalam rumah tangga adalah fondasi masyarakat yang menghargai kehidupan keluarga di atas hampir semua hal. Salah satu aspek yang sangat kontroversial dari Lady Audley's Secret adalah cara tokoh Lucy atau dikenal sebagai Lady Audley membelokkan peran gender tradisional. Lady Audley secara lahiriah memenuhi setiap gagasan Victoria tentang bagaimana seharusnya seorang wanita dan bagaimana dia harus bertindak. Bahkan, Lady Audley menggunakan cita-cita itu sebagai perlindungan atas kejahatannya, menyembunyikan rencana liciknya di bawah topeng wanita masyarakat yang tidak bersalah dan polos.

Apa yang dapat dilihat dalam novel tentang tokoh utama adalah semua hal baik. Lady Audley adalah wanita baik yang telah memiliki kualitas baik sehingga membuat semua orang mengaguminya. Hal tersebut tercermin dari kutipan "„her employer; her visitors; her pupils; the servants; everybody, high and low, united in declaring that Lucy Graham was the sweetest girl that ever lived" (Braddon, 1862). Lady Audley tampaknya mewakili karakteristik perempuan sempurna pada masa itu. Semua 
karakteristik kesempurnaan dari perempuan Victoria tercermin melalui dirinya. Akan tetapi, hal tersebut berubah seiring tekanan yang dia terima dalam menghadapi budaya patriarki yang semakin merendahkan perempuan. Topeng perempuan manis dan polos tersebut berangsur-angsur luntur, memperlihatkan sisi lain dari Lady Audley. Perempuan ini pada akhirnya melakukan pemberontakan terhadap nilai-nilai patriarki masyarakat Victoria. Casey (1984) mengatakan jika alasan pemberontakan ini adalah keterasingan serta tekanan yang diberikan suami perempuan itu. Karena itu Lady Audley diam-diam mengubah pengasingannya menjadi cara manipulasi yang kejam.

Manipulasi yang dilakukan oleh Lady Auldley tidak lain didorong kuat oleh perlakuan sang suami. Banyak narasi dalam novel menunjukkan jika Robert Audley sebagai wakil dari patriarki yang keras dan penuh perhitungan serta dingin. Robert seakan diharuskan menaklukkan Lady Audley, di lain pihak sebagai pria ia harus mengusirnya dari masyarakat terhormat untuk menunjukkan kekuasaannya. Dia ada di sana untuk mengajarinya untuk tunduk sebanyak mungkin. Jelas bahwa Robert adalah perwakilan pria Victoria yang menjunjung nilai patriarki. Seperti dalam kutipan berikut :

God knows I have struggled hard enough against you, and fought the battle patiently enough; but you have conquered, Mr. Robert Audley. It is a great triumph, is it not-a wonderful victory? You have used your cool, calculating, frigid, luminous intellect to a noble purpose. You have conquered-a MAD WOMAN!" (Brodden, 1862:217)

Pengakuan atas kegilaan dalam kutipan di atas menunjukkan bahwa tekanan dari
Robert-yang memegang teguh nilai patriarki-telah mengarahkan Lady Audley untuk melabeli dirinya sendiri sebagai "orang gila". Perempuan ini terkonstruksi oleh Robert sebagai sang dominan agar menyetujui kegilaan yang dirasa mulai dialaminya. Budaya dalam masyarakat tersebut memberikan kuasa terhadap laki-laki agar selalu menjadi pemenang. Menurut Focault, kegilaan tetap melekat pada perspektif budaya. Ketika suatu budaya menilaimu salah maka dirimu merupakan orang yang salah, meski pada hakikatnya seseorang itu merasa apa yang dilakukannya adalah benar. Di samping itu, perempuan pada era Victoria seperti penjelasan sebelumnya memang selalu diletakan pada subordinat. Bahkan untuk merendahkan lagi, ada perkataan dari Robert "I hate women," he thought, savagely" (Braddon, 1862). Kalimat ini mengungkapkan kecenderungan misoginis Robert. Dia berpikir bahwa wanita bertanggung jawab untuk menciptakan masalah dan mereka menipu dan memanipulasi pria, memaksa mereka ke dalam situasi yang sulit.

Ketika Lady Audley dirasa memunculkan kesulitan bagi Robert, itu sama dengan menggiring sang perempuan masuk ke dalam golongan orang-orang marginal karena dianggap tidak sesuai dengan norma yang diciptakan para laki-laki. Diperburuk lagi ketika Lady Audley mendeklarasikan dirinya sebagai seorang pembunuh. Hal tersebut terlihat dalam kutipan berikut :

"When you say I killed George Talboys, you say the truth. When you say that I murdered him treacherously and foully, you lie. I killed him because I AM MAD! because my intellect is a little way upon the wrong side of that narrow boundary line between sanity and insanity; because when George Talboys goaded me as you have goaded me; and reproached me, and threatened me; my mind, never properly 
Poetika : Jurnal Ilmu Sastra

Vol. 8 No. 1, Juli 2020

balanced, utterly lost its balance; and I was mad!" (Braddon, 1862:355)

Bagian ini melambangkan klimaks dari novel tersebut, ketika Lady Audley menyadari bahwa dia tidak dapat lagi berusaha untuk menyembunyikan rahasianya dari Robert dan mengakui perannya dalam kematian George. Bahkan pada saat ini, bagaimanapun, dia tidak bertanggung jawab penuh atas tindakannya, dia mengaku sebagai korban kegilaan, dan juga beralasan bahwa dia menyerang karena dia dianiaya oleh George. Kutipan ini mengundang pembaca untuk mempertimbangkan pendapat mereka sendiri tentang kesalahan dan tanggung jawab Lady Audley. Ini juga menggemakan gagasan bahwa kewarasan dan kegilaan sedang berubah konstruksi.

Sebelumnya, ketika Lady Audley melakukan beberapa kesalahan, dia sendiri menganggap dirinya sebagai orang gila dan untuk membenarkannya dia mengatakan ibunya juga sudah gila. Karena alasan ini dia dianggap gila. Lady Audley harus dikubur hidup-hidup di rumah sakit jiwa karena menurut dokter, dia adalah wanita yang berbahaya. Menempatkan Lady Audley ke rumah sakit jiwa adalah cara untuk menghentikan perilakunya yang memalukan dan merusak karakter bangsawan, khususnya pasangannya Sir Michael Audley. Lady Audley dimasukkan ke rumah sakit jiwa karena dia ditemukan menjadi penjahat ganas yang tidak hanya berusaha melakukan pembunuhan tetapi juga menikahi pria lain sementara secara bersamaan telah menjadi istri orang lain dan meninggalkan anaknya. Ada percakapan antara Dr. Mosgrave dan Robert dalam novel yang subjeknya adalah Lady Audley:
DOI $10.22146 /$ poetika.56544

ISSN 2338-5383 (print) ; 2503-4642 (online)

Dr. Mosgrave:

Because there is no evidence of madness in anything she has done. She run away from her home, because her home was not a pleasant one, and she left in the hope of finding a better. There is no madness in that. She committed the crime of bigamy, because by that crime she obtained fortune and position. There is no madness there. When she found herself in a desperate position, she did not grow desperate. She employed intelligent means, and she carried out a conspiracy which required coolness and deliberation in its execution. There is no madness in that.

Robert:

"But the traits of hereditary insanity" (Braddon, 1962:236)

Alasan Lady Audely dianggap gila adalah karena dia tidak bertindak seperti wanita yang rendah hati seperti wanita lain. Dengan kata lain, dia tidak berperilaku sesuai dengan norma -norma masyarakat Victoria dan karenanya dia dianggap gila. Rumah dan masyarakat di zaman Victoria dianggap sebagai perlindungan dari bahaya dari dunia luar. Namun dalam novel tersebut, Lady Audley yang baik dan sempurna adalah seorang wanita ganas yang tidak hanya melakukan upaya pembunuhan tetapi juga telah melakukan perzinaan dan meninggalkan anaknya. Novel ini menunjukkan bagaimana masyarakat Victoria terganggu ketika ide dan konsep mengenai wanita/ibu yang sempurna dan kebahagiaan rumah tangga tidak dipatuhi oleh Lady Audley. Karena itu Lady Audley bukan contoh sempurna malaikat di rumah. Karena alasan tersebut, Lady Audley diyakini sebagai wanita gila dengan ambisi buruk.

Di samping itu, karena orang-orang yang hidup pada era Victoria tidak sepenuhnya memahami penyakit mental, gejalanya sering diklasifikasikan sebagai kegilaan yang tak tersembuhkan dan tidak dapat dikelola. Kegilaan tersebut dianggap berasal dari penyimpangan moral dan ketidakmampuan untuk menyesuaikan diri dengan masyarakat. 
Tanpa kriteria ketat untuk mendiagnosis kegilaan, tuduhan yang tidak berdasar dapat menyebabkan pelembagaan dengan relatif mudah. Kesalahan pengelompokan seperti itu menyebabkan efek negatif yang bertahan lama bagi karakter Lady Audley, bahkan ketika tuduhan kegilaan yang dibuat oleh Robert dinilai menawarkan solusi jangka pendek untuk masalah yang mendesak. Pengakuan Lady Audley tentang kegilaannya sendiri, membantunya mengalihkan kesalahan atas tindakan kriminalnya dan juga menyebabkan hilangnya kebebasannya.

Lady Audley dimasukkan ke rumah sakit jiwa yang membuatnya menjadi pasif atau tidak aktif. Ketidakaktifan ini akan membunuhnya karena dia tidak dapat berkomunikasi dengan teman dan kerabatnya. Itu adalah cara paling efektif untuk menghancurkan wanita seperti Lady Audley. Ini juga dibuktikan oleh Robert Audley sendiri ketika berkata:

"From the moment in which Lady Audley enters that house," he said, "her life, so far as life is made up of action and variety, will be finished. Whatever secrets she may have will be secrets forever! Whatever crimes she may have committed she will be able to commit no more. If you were to dig a grave for her in the nearest churchyard and bury her alive in it, you could not more safely shut her from the world and all worldly associations. But as a physiologist and as an honest man, I believe you could do no better service to society than by doing this; for physiology is a lie if the woman I saw ten minutes ago is a woman to be trusted at large. If she could have sprung at my throat and strangled me with her little hands, as I sat talking to her just now, she would have done it." (Braddon, 1862:239)

Dari sudut pandang Lady Audley, menjadi tidak aktif berarti sama saja dengan dikubur hidup-hidup di rumah sakit jiwa. Lady Audley berkata kepada Robert Audley bahwa dia telah membawanya ke kuburnya. Bahkan sistem patriarki memaksakan kepasifan padanya sebagai hukuman atas kejahatannya. Membunuh tubuhnya secara tidak langsung tidak akan terlalu menyakitkan baginya, akan tetapi kepasifan dalam rumah sakit jiwa itu justru lebih menyiksa. Mereka membuat Lady Audley mati perlahan dan bertahap-yang sangat menyiksa jiwa.

\section{Simpulan}

Novel ini sangat peduli dengan subjek kegilaan dan perlakuan terhadap orang gila, dan subjek ini tidak pernah terpisah dari pertimbangan peran nilai serta norma pada era Victoria. Beberapa karakter dituduh gila atau diancam dengan komitmen akan dimasukkan ke rumah sakit jiwa contohnya seperti ibu dari Lady Audley. Ibunya dilembagakan setelah kelahiran putrinya karena permulaan dari apa yang akan disebut pengobatan modern sebagai bentuk ekstrim dari depresi post-partum (depresi pasca-melahirkan). Selain itu, Lady Audley berdalih bahwa tindakan tidak manusiawi seperti pembunuhan dan pembakaran yang dilakukannya disebabkan oleh kegilaan, dengan demikian hal tersebut membebaskannya dari rasa bersalah. Namun, pada akhirnya Lady Audley ditempatkan di Maison de Santé di Belgia untuk mengakhiri hari-harinya dalam ketidakjelasan.

Di samping itu, kegilaan dan tekanan dari norma serta budaya yang ada terkait erat di era Victoria dimanifestasikan sedemikian rupa sehingga citra diri berhubungan dengan dunia luar. Akibatnya, kegilaan terdiri dari gagasan dan perilaku yang muncul dari perasaan diri yang tidak lurus. Tokoh utama dalam novel memperlihatkan bahwa tekanan yang terjadi membuatnya perlahan berubah menjadi orang yang benar-benar di luar akal sehat. Pembunuhan serta pembakaran yang 
dilakukannya tidak hanya membuatnya dilabeli dengan orang gila namun juga merupakan tindakan kriminal.

\section{Daftar Pustaka}

Anggradinata, Langgeng Prima. 2016. Konsep Kegilaan dan Kekuasaan Michel Foucault dalam Cerpen "Catatan Harian Orang Gila" Karya Lu Xun. Wahana. Volume 1, No. 13.

Braddon, Mary Elizabeth. 1862. Lady Audley's Secret. Leipzig: Tauchnitz

Bernstein, Susan David. 1994. "Dirty Reading: Sensation Fiction, Women, and Primitivism." Criticism 36.2.1994: 213-41. ProQuest. Web. 31 Mei 2020

Casey, Ellen Miller. 1984. "'Other People's Prudery": Mary Elizabeth Braddon". Sexuality and Victorian Literature. Ed. Don Richard Cox. Knoxville: $U$ of Tennessee $P$
Faruk. 2012. Metode Penelitian Sastra: Sebuah Penjelajahan Awal. Yogyakarta: Pustaka Pelajar.

Foucault, Michel. 1989. Madness and Civilization: A History of Insanity in the Age of Reason. VintagePress

Foucault, Michel. 2002. Pengetahuan dan Metode: Karya-Karya Peting Michel Foucault. Yogyakarta : JALASUTRA

Hayes, Corey. 2014. The Beauty and the Barrister Gender Roles, Madness, and the Basis for Identity in Lady Audley's Secret. Unpublished senior thesis : Liberty University

Moqari, Shaqayeq. 2015. Representation of Mad Woman in Lady Audley's Secret by Mary Elizabeth Braddon. World Scientific News Journal. EISSN 2392-2192

Ritzer, George. 2009. Teori Sosial Postmodern. Yogyakarta : Kreasi Wacana 